\title{
El mejor poeta en España del año 1900
}

\author{
GeOFFrEy RibBans
}

BROWN UNIVERSITY. PROVIDENCE

Primero, debo hacer una advertencia previa: esta comunicación es más bien una charla, sin pretensiones de erudición o investigación, y aspira sólo a ofrecer algunas ideas que pudieran servir de estímulo o aliciente para estudios más profundos.

No seré yo el único que haya advertido un fenómeno muy curioso dentro del desarrollo de las culturas hispánicas: el hecho de que, en ciertos momentos de desorientación o de pérdida de rumbo de la literatura mayoritaria, las culturas marginales o periféricas, en marcado contraste con la cultura oficial, parecen revestirse de nueva vida. Parece que acuden - para decirlo así- a llenar el vacío, si bien esto no ha sido su objeto.

Las razones no son difíciles de encontrar. Cada cultura diferenciada sigue su propio ritmo interno, según un impulso dinámico o debilitado que procede de su evolución interna, sin intervención de factores que vienen desde fuera. Pero no sólo depende este desarrollo de consideraciones literarias sino de estímulos sociales y ambientales, que podrían ser muy distintos de los del conjunto nacional. Me parece claro, por eiemplo, que una lírica tan poderosa como la de Rosalía de Castro no surge del aire; tanto la boga que gozaba entonces la poesía popular en general como la evolución especial de la lírica gallega conducían a este florecimiento. Al mismo tiempo, y con no menos fuerza, las crecientes olas de protesta y de reivindicación política dictadas en parte al menos por la situación marginada del campesinado gallego producen un clima propicio a una manifestación cultural ${ }^{1}$.

Indudablemente la creciente industrialización de Cataluña durante el siglo XVIII dio lugar, primero, a una notable ampliación de los estudios históricos

\footnotetext{
' Para un rápido enfoque sobre el proceso de la recuperación lingüística en Cataluña y Galicia, véase mi "Renaixença/Rexurdimento: lírica catalana, lírica galega," Actas do Segundo Congreso de Estudios Galegos (Brown University, 1988), ed. Antonio Carreño. Vigo, Galaxia, 1990, págs. 35-57.
} 
de tipo comercial y político y luego a las primeras iniciativas de la Renaixença. Asimismo, no es nada fortuito que el País Vasco, y especialmente Bilbao, centro de una nueva sociedad industrial, con fuertes cambios demográficos y marcadas discrepancias ideológicas, sea a finales del siglo XIX cuna de un activo grupo de escritores y artistas, tales como Unamuno, Maeztu, los hermanos Baroja y Zuloaga.

Pasemos al tema específico de mi charla, que es contemporáneo al desarrollo vasco y radicado en otra zona industrializada, Barcelona y su comarca, caracterizada por cierto por su empuje empresarial y modernizador. El ritmo del progreso de la cultura catalana a lo largo del siglo XIX es muy distinto del de la castellana, desde múltiples puntos de vista: ideológicos, temáticos, artísticos, lingüísticos. Se cultivan en Cataluña con predilección formas con índole distinta como la novela histórica, la poesía épica, el drama rural, una lírica clasicista, estudios de filosofía, historia y filología, además de una verdadera explosión de las artes plásticas y la música. La poesía lírica también evoluciona de modo muy especial.

Con esto llego a mi título, con su brusca afirmación y deliberada falta de explicación. Lo que podría ser, en una reunión más amplia, algo enigmático o polémico, no creo, dentro del contexto de este coloquio, que ofrezca grandes problemas. Se trata, desde luego, de Joan Maragall. Aparte de contar con el respaldo de un crítico de la categoría de Dámaso Alonso ${ }^{2}$, no me parece nada difícil justificar tal aserto. Se advierte en seguida una extraordinaria falta de competencia. Al referirme a "poeta en España" y no "poeta en español" queda excluido un hispanoamericano como Rubén Darío. Por no ser un poeta en plena producción activa en 1900, cae fuera de la cuenta Antonio Machado, que tenía entonces 25 años, pero que apenas había publicado nada, y también Juan Ramón Jiménez, muy precoz, pero que sólo tenía 19 años. Con sus 36 años a cuestas, Unamuno todavía no se había destacado como poeta. La figura consagrada de la época fue Núñez de Arce, que según unánime consenso posterior, no merece entrar en la contienda. Otro candidato posible, "Mossen Cinto", Verdaguer, vivía aún, pero se le va terminando su carrera poética. Si hubiéramos retrocedido la fecha que empleamos a 1885 ó 1890 , creo que él hubiera sido el escogido, como en 1880 habríamos de optar por Rosalía de Castro; o para el siglo XV, Ausiás March. Pero dejemos estas especulaciones tan generalizadas, con esa palabra catalana tan expresiva: Prou.

$\mathrm{Y}$ al hablar de Maragall, hemos de recordar que no era exclusivamente un poeta. Su poesía ocupa sólo uno de los 25 volúmenes de que consta sus Obres completes, en la Edició dels Fills, si bien otros tomos están dedicados a traducciones en verso. De sus artículos de prensa, los tres cuartos están escritos en

2 "Lo infinito y lo realista (a su molde) en la poesía de Maragall," Cuatro poetas españoles. Madrid, Gredos, 1963, págs. 81-133, y "La poesía de Joan Maragall," Joan Maragall. Conferencies en commemoració del centenari de la seva naixença (1860) y del cinquantenari de la seva mort (1911). Barcelona, Institut d’Estudis Catalans, 1963, págs. 97- 134. 
castellano, la mayoría para el Diario de Barcelona, llamado familiarmente el Brusi. Lo curioso y lo lamentable es que sus ensayos en castellano, muy perspicaces y coherentes, son muy poco conocidos en el resto de España, como en su tiempo indicó Unamuno ${ }^{3}$. Más allá de la barrera lingüística, que históricamente impedía la entrada de la literatura en catalán en el resto de España, había también una barrera geográfica e ideológica, que estorbaba tan eficazmente la penetración de escritos en castellano ubicados en Cataluña. Si no fuera así, creo que al Maragall ensayista en castellano le correspondería un puesto mucho más destacado de lo que ha conseguido, bastante más alto-y aquí pongo un solo nombre, a título de ejemplo-que Ramiro de Maeztu. Aun cuando se le reconoce a Maragall su estatura, como se han esforzado a señalar, entre otros, Dámaso Alonso, ya aludido, y Pedro Laín Entralgo ${ }^{4}$, se le trata las más veces como miembro catalán de la Generación del 98 . Es una caracterización que me parece errónea, porque pasa por alto el hecho fundamental de que Maragall y sus coetáneos catalanes no se consideraban a sí mismos como comprometidos o responsables en el "Desastre." No se sentían parte de la tradición que lo había producido, sino de otra nueva, no puesta en práctica todavía, pero que ellos estaban ávidamente formulando. Mientras Maragall no se apartaba del todo de España y sus angustias, el desastre constituía para él la derrota de una larga tradición histórica que a los catalanes les eran ajenos. Si "me duele España" es un resumen adecuado de la actitud emocional de la Generación del 98 en conjunto, "la triste y espaciosa España" es para Maragall algo menos de la mitad de su propia realidad. La fórmula para éste sería más bien: "honda compasión siento hacia España, pero lo que me anima es Cataluña." Al contrario de la índole pesimista de la Generación, Maragall se destaca por su optimismo.

Volvamos ahora a su poesía. El hecho es, pues, que en este género Maragall contaba con muy poca competencia, por ser la época en que empezaba a florecer una de las más desoladoras de la poesía lírica castellana. Fue el resultado sin duda, entre otras cosas, del culto sostenido de la retórica y la complacencia estética característica de la Restauración. Lo cierto es que no me interesa rebajar a Maragall, destacándole por la ausencia de otros mejores: es mucho más que el mejor de una generación mediocre.

¿Cuáles son, en definitiva, las cualidades positivas de su poesía? Una que se destaca es la íntima correlación entre sus teorías teóricas y su práctica poética ${ }^{5}$.

\footnotetext{
3 "Un hecho triste", en Unamuno-Maragall, Epistolario y escritos complementarios. Madrid, Seminarios y Ediciones, 1971, pág. 143, y Maurici Serrahima, Realidad de Cataluña. Barcelona, Aymá, 1967, págs. 147-53.

+ Según Laín Entralgo, "Maragall es la versión catalana, más aún, la versión catalanista, de esa cgregia generación" (pág. 1 1), pero la rectificación es significativa, "Prólogo", Unamuno-Maracall, Epistolario, págs. 11- 17.

5 Véanse Arthur Terry, La poesia de Joan Maragall. Barcelona, La Revista, 1963, y mis artículos "La poesia de Maragall dins el context del simbolisme europeu", Actes del Quart Col.loqui Internacional de Lengua i Literatura Catalanes (Basilea, 1976), Montserrat, Abadia, 1977, págs. 395-406, "Maragall i les teories estètiques del romanticisme," Actes del Segon Col.loqui d'Estudis Catalans a Nord-América (Yale, 1979), Montserrat, Abadia, 1982, págs. 239-245.
} 
Se han criticado mucho estas teorías, especialmente tal como se expresan en los Elogis, por ingenuas y arbitrarias, y tales críticas no dejan de tener razón, si se les considera como normas objetivas que rigen la escritura poética. El culto de la pura espontaneidad, condensado en el criterio de "la paraula viva," es poco adecuado como método de enjuiciar la poesía, pero sí sirve para señalar las prioridades que gobiernan la práctica poética del poeta. Ilustra, por ejemplo, el grado de concentración y precisión emocional que Maragall aspira a captar en sus versos. Y no cabe duda de que en este esfuerzo le ayudó poderosamente el empleo de una lengua que, ya flexible y en gran medida confiada en sí misma, carecía casi por completo de una tradición retórica inmediata - la más lejana del soberbio antecedente medievai constituía una ventaja, no un estorbo- esa tradición retórica que pesaba tan fatalmente sobre el castellano ochocentista. Como consecuencia Maragall escribe con una confianza y falta de afectación que no excluye una actitud bastante inconsecuente a la cuestión de la pureza lingüística. Actitud, a fin de cuentas, que no tiene la importancia que se lo asigna a veces. A causa de su culto a la espontaneidad intuitiva Maragall sabe enunciar con seguridad las afirmaciones más sencillas: "un prat ben verd, sota d'un cel ben blau"; "Ets el cel blau, ets l'arbre verd, ets el meu sol." Se permite hacer preguntas familiares, sin asomo de afectación: "No sents una frisança, dona?"; "Saps on és la fageda d'en Jordà?" Su poesía abunda en aquellas exclamaciones que reúnen reverencia e intensidad: "Quin cel més blau aquesta nit!"; "Mar blava, mar verda, mar escumejanta!"; "la ginesta, altra vegada, la ginesta amb tanta olor!" $\mathrm{Y}$ el ingenuo convencimiento de que existe una emoción poética pura y espontánea le permite sintetizar en una frase la experiencia sentida:

Oh companyia! Oh deslliurant presó!

Barcelona! amb tos pecats, nostra! nostra!

Barcelona nostra! la gran encisera!

Sia'm la mort una major naixença!

La preocupación por la espontaneidad trae consigo un afán hacia la emoción pura, hacia la búsqueda de una núcleo irreducible de experiencia poética, que anticipa en cierto grado la poésie pure de Paul Valéry. En otros aspectos, por cierto, la poética maragalliana difiere mucho de esta tendencia, por enlazarse estrechamente con el impulso emocional de los primeros románticos alemanes y por su carencia absoluta de intelectualización. Por eso rechaza a los parnasianos por demasiado cerebrales e identifica la pureza que busca, de un modo algo superficial, con la poesía popular. Y si bien procura reducir la poesía a su núcleo esencial, como se advierte en las tres expresiones evocadoras que cita en el Elogi de la paraula: "aquella canal," "les esteles," "Mira,"-en esto le aplaudiría Jorge Guillén- no participa de ninguna forma del anhelo simbolista de abolir la anécdota. En él, por contraste, permanece siempre la anécdota, subordinada al efecto emocional de la experiencia poética. Así, en "Ell parla," la vislumbre de la primera alondra de la primavera redime toda la frustración acumulada del invierno. En otros poemas, por ejemplo, "La nit de 
la Puríssima" o "La fageda d'en Jordà," se da una concentración sobre el punto de sensación más intenso, el cual se somete a un proceso de purificación y de concentración, pero no se desliga, como en los simbolistas, de las circunstancias que lo producen. Hay sin embargo curiosos paralelos con los tópicos simbolistas, como el culto de la danza, una forma "auto-engendrada," en la que se identifica el autor con la forma, el cuerpo con el espíritu. Es una aproximación de gran importancia en un hombre como Maragall, a la vez sensual y espiritual. Así, su enfoque es paralelo a los grandes movimientos literarios de su tiempo, si bien independiente de ellos.

Otra preocupación contemporánea muy diferente que podemos rastrear en Maragall es el afán constante hacia la renovación: un impulso dinámico que podría relacionarse con Nietzsche, que tanta huella dejó en el joven barcelonés ${ }^{6}$. Va unida asimismo con la permanente influencia de su querido Goethe; es uno de los pocos españoles imbuidos a fondo con el sabio de Weimar. $\mathrm{Su}$ concepto de la vida como un constante esfuerzo hacia adelante tiene poderosas reminiscencias goethianas. Es verdad que a veces siente la tentación de querer parar el curso del tiempo, como cuando en el "Cant espiritual" afirma que:

Aquell que a cap moment li digué, "-Atura't" sinó al mateix que li dugué la mort, jo no l'entenc, Senyor; jo, que voldria aturar tants moments de cada dia per fê'ls eterns a dintre del meu cor!...

Fausto muere cuando ya no anhela el cambio. "O és que aquest 'fê etern' és ja la mort?" es la pregunta correspondiente en el "Cant espiritual," que plantea el problema sin resolverlo.

En sus mejores momentos este afán renovador maragalliano adquiere una dimensión moral y la aspiración surge, no sólo hacia adelante, sino hacia arriba. El lema del poeta se convierte en excelsior. Como escribe en 1900, "La obra que representa mejor mis ideas es siempre la última que escribo, porque pretendo hacer de mi vida un continuo excelsior, sin estancarme nunca"? O como proclama en el poema que lleva este título:

Fora terres, fora platja, oblida't de tot regrés:

no s'acaba el teu viatge, no s'acaba mai més.

\footnotetext{
${ }^{6}$ Consúltense EduARD VALENTi, El primer modemismo literario catalán y sus fundamentos ideológicos. Barcelona, Ariel, 1973, págs. 327-36, y Gonzalo Sobejano. Nietzsche en España. Madrid, Gredos, 1967 , págs. 35-40; 84-85.

${ }^{7}$ [Carta a Federico Urales], Federico Urales, La evolución de la filosofia en España. Barcelona. La Revista Blanca, 1934, pág. 247.
} 
Tal aspiración hacia la renovación esconde sin embargo una potencialidad, por otra parte inevitable y necesaria, hacia la intranquilidad, la indisciplina y el egoísmo. Es una combinación insólita y apenas esperada en un arquetipo del padre de familia burgués ${ }^{8}$. Llega hasta abrazar la rebeldía y las actitudes de subversión e insolencia que encontramos en el bandido Joan Serrallonga, en Fra Garí y sobre todo en el comte Arnau. Sin este individualismo extremado, según el sentir de Maragall, la sociedad humana se hundiría en la indulgencia y la complacencia. Los instintos vitales hay que reconocerlos y aceptarlos antes de que puedan ser sojuzgados y convertidos en un dinamismo espiritual, en el espíritu exaltante de excelsior. Como se explica de Joan Garí: "ja pots alçâ els ulls al cel,/ que ja els tens prou plens de terra." Sólo entonces puede el hombre alcanzar el equilibrio y la serenidad que encuentra su suprema expresión en la etapa final de Goethe. Tras largo caminar, tras la contrición ineludible y el amor de una mujer pura, el Comte Arnau puede ganar la redención. Es este distintivo enlace del individualismo agresivo con la necesidad de reconciliar por fin el yo individual con los valores colectivos - un peregrino consorcio de Goethe y Nietzsche - lo que da a la ideología maragalliana su calidad especial. La justificación de la poesía reside no obstante en la expresión poética y no en su contenido. Por eso conviene que veamos unos pocos ejemplos concretos.

Primero, un poema titulado "Paternal," con el subtítulo "Tornant del Liceu en la nit del 7 de novembre de 1893": fecha significativa, como veremos. Empieza así:

Furient va esclatant l'odi per la terra, regalen sang les colltorçades testes i cal anâ a les festes amb pit ben esforçat, com a la guerra.

Al soltarse el odio, se nos da una descripción viva y horripilante de las cabezas sangrientas con los cuellos rotos (muy expresivo en catalán: "colltorçades). El ir al teatro es como ir a la guerra: la escena es evidentemente la del célebre atentado anarquista contra el Liceo, en el que murieron unas veinte personas; Maragall y su esposa asistieron, pero salieron ilesos. Sigue el poema:

A cada esclat mortal - la gent trèmula es gira:

la crudeltat que avança - la por que s'enretira, se van partint el món;

Mirant el fill que mama - a la mare que sospira, el pare arruga el front.

La gente queda escindida, la crueldad de un lado, el temor de otro; y el padre, sumamente patriarcal en su hogar, siente inquietud. Hasta ahora un

\footnotetext{
${ }^{8}$ Véase JoAN-Lluís MARFAnY, "Maragall, poeta regeneracionista," Aspectes del modernisme, Barcelona, Curial, 1975, págs. 99-121.
} 
poema discreto, sobre la discordia social, sin estridencia, con sorprendente ecuanimidad frente al terrorismo; y un escenario burgués, que tal vez resulta complaciente. Reza la última estrofa:

Prô l'infant innocent, que deixa, satisfet, la buidada mamella, se mira an ell - se mira an ella, i riu bàrbarament.

El niño de pecho es inocente, bien nutrido, contento con sus padres, pero la palabra clave es la última: "bàrbarament"9. Aún un crío todavía sin malicia tiene la potencialidad de ser bárbaro, de acuerdo con la violencia polarizadora que es el tema latente del poema.

Algo por el estilo podría decirse de la "Oda nova a Barcelona," en la cual Maragall acoge todas las facetas de la ciudad, buenas y malas, como parte de la realidad humana y toponímica de una nueva Cataluña, la que urge aceptar tal como es. Es otra ocasión en que un evento político se impone sobre la estructura del poema; medio acabado el poema en la época de la Semana Trágica en $1909^{10}$, Maragall no permite que la agonía del momento disminuya su celebración de la ciudad, como una realidad radicalmente imperfecta pero entrañablemente humana: "Barcelona! i amb tots tos pecats, nostra! nostra! / Barcelona nostra! la gran encisera!"

Las composiciones que redactó Maragall sobre "el Desastre," los tres "Cants de la Guerra," son para mí los documentos más conmovedores que se produjeron sobre aquella guerra. Uno que describe el regreso de los soldados derrotados, "de la trista lluita sense fe ni glòria / d'un poble que es perd." Continúa con una nota más positiva. Si el país tiene la fuerza moral de abandonar una trayectoria falaz, evidentmente el imperialismo castellano, y mirar hacia el futuro, que depende de los recursos naturales de la tierra, y que corresponde a lo que Maragall entiende como política catalana, entonces, y sólo entonces, se sustituirán por los llantos risas y cantos.

La última característica de la poesía maragalliana que me interesa destacar es la atención afectuosa que presta a todos los aspectos de la existencia física, sea que ésta tome la forma de la naturaleza, el amor, el hogar y la satisfacción doméstica, la patria y los valores cívicos -elementos todos que fluyen con toda naturalidad el uno en el otro en una secuencia continua. Todos ellos constituyen una fuerza espiritual todopoderosa que da luz a lo que se suele llamar su "panteísmo," concepto que abarca tanto la unidad esencial de toda expe-

\footnotetext{
"Véanse mi artículo "La propaganda pel fet': Some notes on the effect of Anarchist terrorism on the Catalan bourgeoisie of the late nineteenth century," Actes del Tercer Collogui d'Estudis Catalans a Nord-Amèrica (Toronto, 1982), Montserrat, Abadia, 1983, págs. 289-302, y Terry, págs. 92-95.

${ }^{10}$ Consúltese el estudio detallado de Josep Benet, Maragall i la Setmana Tràgica. Barcelona, Institut d'Estudis Catalans, 1963, págs. 65-68.
} 
riencia y la omnipresencia de Dios. Los anhelos espirituales maragallianos se expresan siempre en términos esencialmente físicos y no son nunca abstractos; más que transcendentes, son, para acuñar una expresión idónea, "intercendentes." Hay una interrelación permanente y constante entre la vida de la carne y la del espíritu: el mundo es y debe ser la medida de las aspiraciones espirituales de los que son seres humanos. La síntesis de todas estas ideas se encuentra, desde luego, en "El cant espiritual", demasiado conocido para que yo vuelva a citarlo ahora.

A fin de cuentas, la poesía de Joan Maragall revela una amplitud de visión poética, una seguridad de expresión y una aspiración idealista individual que corre parejas a las principales corrientes de teoría poética y filosofía vitalista del ochocientos. Logra evitar lo que para mí es la falsa dicotomía entre los valores estéticos y sociales que dividieron a tantos escritores de la época. Para Maragall no existe incompatibilidad entre la visión poética introspectiva y las obligaciones cívicas; en términos de la ortodoxia crítica hispánica no se le puede encasillar de modo satisfactorio o exclusivo en ninguno de los movimientos tan consagrados como falsos, que son el modernismo y la Generación del $98^{11}$. Lo que resulta es que Maragall no sólo es el mayor poeta en España a los albores del siglo XX - lo que no es en sí gran cosa - sino que se encuentra, a mi modesto parecer, en la selecta compañía de los ocho o diez poetas españoles principales de la época moderna, capaz de no ir a la zaga de los mejores, entre los cuales para mí entrarían en amistosa contienda Antonio Machado, Juan Ramón Jiménez, Unamuno, Guillén, Lorca, Cernuda, en lengua castellana, y, entre los catalanes, Carles Riba, J. V. Foix y, más tarde - ¿qué sé yo? - tal vez Pere Gimferrer.

1 Para mi opinión sobre tan dudosa dicotomía, véanse "Some subversive thoughts on modernismo and the Generation of "98", Philological Papers (West Virginia), 39 (1993/1994), págs. 1-17, y "Apunts sobre el modernisme hispanoamericà i el modernisme català". Miscel.lania d'Homenatge a Joan Triadí amb motiu del seu setantè aniversari. Ed. Albert Manent and Ramon Pla. Barcelona. 1993, págs. $89-94$. 